\title{
DESIGN OF WEARABLE ANTENNAS FOR 5G APPLICATIONS
}

\author{
Narukurthi Vivek, Sandeep Kumar B, Dr K. Shambavi \\ Department of Electronics and Communication Engineering, \\ School of Electronics Engineering (SENSE), \\ Vellore Institute of Technology, Tamil Nadu, India.
}

\begin{abstract}
Design for wearable micro strip antennas which operate at frequencies of $3.5 \mathrm{GHz}$ and $28 \mathrm{GHz}$ which falls under the sub-6 GHz spectrum and mm Wave spectrum of the $5 G$ frequency bands respectively, has been proposed in this article. The antennas are mounted on a polycarbonate substrate of dielectric constant 2.57, thickness $0.5 \mathrm{~mm}$ and dielectric loss tangent of 0.0069. Antenna 1 resonates at a frequency of $3.466 \mathrm{GHz}$ and its operating bandwidth ranges from 3.445 to $3.487 \mathrm{GHz}$ (1.2\%) with a peak gain value of $8.018 \mathrm{dBi}$ and Antenna 2 resonates at a frequency of $28.36 \mathrm{GHz}$ with its operating bandwidth ranging from 27.604 to $29.094 \mathrm{GHz}(5.2 \%)$ and attains a peak gain value of $8.886 \mathrm{dBi}$. Within the operating bandwidth ranges of both the antennas the gain is almost constant and hence the proposed design can be used in various sectors such as healthcare, sports military etc.
\end{abstract}

Key words: Wearable antennas, Polycarbonate, Micro strip, Bandwidth, Resonant frequency, $5 \mathrm{G}$ frequency bands

Cite this Article: Narukurthi Vivek, Sandeep Kumar B, K. Shambavi, Design of Wearable Antennas for 5G Applications, International Journal of Electrical Engineering and Technology (IJEET), 12(5), 2021, pp. 148-156. https://iaeme.com/Home/issue/IJEET?Volume=12\&Issue $=5$

\section{INTRODUCTION}

As time approaches the demand for higher speed, better reliability, large storage capacity and better connectivity for large data rates has also been increasing, which can be attained with the help of 5G technologies and can be incorporated using internet of things (IOT) [1-3]. The 5G technology can provide up to $10 \mathrm{Gbps}$ data rate which is approximately 10 times the data rate provided by the present 4G-LTE technologies [4]. To satisfy the demands of the growing wireless communication, the Federal Communication Commission has launched to include the high frequency bands $(20-80 \mathrm{GHz})$ along with the sub-6 GHz frequency spectrum for the $5 \mathrm{G}$ communications [5]. The Body Area Network (BAN) would fall under this frequency spectrum, microelectronics has seen great advancements in this era which paves the way for BANs which can be widely used for various human requirements like precisely monitoring various human 
activities such as running, walking and climbing stairs, BANs are used to monitor the health care parameters such as heartbeat, temperature etc., [6-8]. There are various applications of wearable antennas which are already in use such as smart watches [9], button antennas [10], smart wrist bands [11] and spectacles [12]. There have also been instances where antennas are directly attached to the skin, for purposes like tracking location with the help of GPS etc., [13].

In this article the operating frequencies has been chosen very carefully, which are $28 \mathrm{GHz}$ (there are proven results that rain and air attenuation is comparatively very less in the frequency range of $28 \mathrm{GHz}$ to $38 \mathrm{GHz}$ [14-15]), and $3.5 \mathrm{GHz}$ (to show that the design is effective in the sub-6 GHz frequency spectrum as well), micro strip antenna type has been chosen in this design for its various advantages such as simplicity of its fabrication, low profile and physical size [14].

The proposed design of antenna can be reused, which means the mountable antenna can be removed from one individual and used by the other, or it can be used for various devices moving from one to another. The dimensions of the antenna and inset feed were calculated using transmission line model method. The antenna characteristics were studied using the software tool CST (Computer Simulation Technology) Studio Suite 2019.

\section{DESIGN OF ANTENNAS}

Square patch (Antenna 1) and rectangular patch (Antenna 2) antennas have been proposed in this paper that operates at $3.5 \mathrm{GHz}$ for sub-6GHz $5 \mathrm{G}$ applications and $28 \mathrm{GHz}$ for $5 \mathrm{G}$-millimeter wave applications respectively. The substrate material chosen for both antennas was Polycarbonate keeping in mind the fact that it is well suited for wearable purposes, it has a relative permittivity of 2.57, 0.0069 loss tangent and a thickness of $0.5 \mathrm{~mm}$. Based on the transmission line model, square patch (Figure 1.) and rectangular patch (Figure 2.) dimensions were calculated for $3.5 \mathrm{GHz}$ (Table 1.) and $28 \mathrm{GHz}$ (Table 2.).

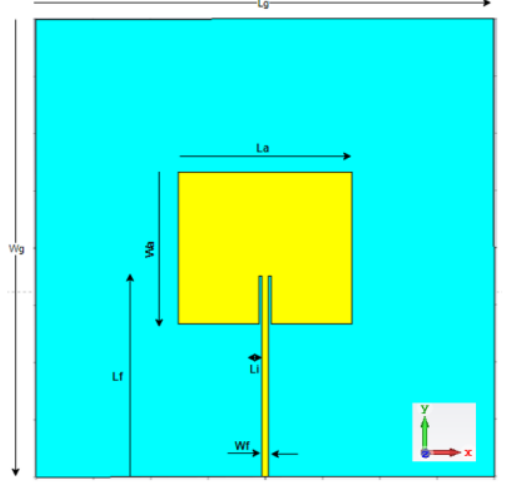

Figure 1 Geometry of Antenna 1

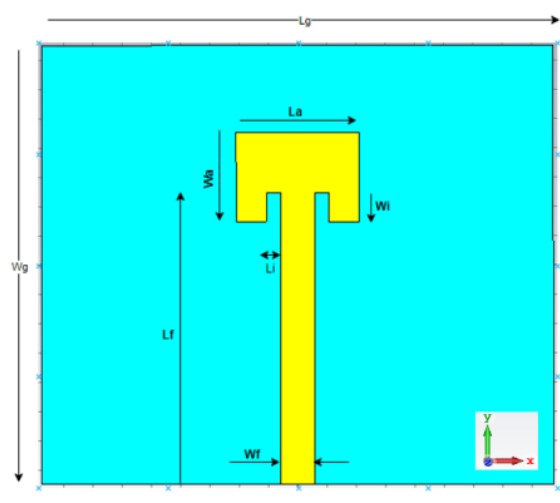

Figure 2 Geometry of Antenna 2

\section{PARAMETRIC ANALYSIS}

Parametric analysis was done using CST Studio Suite 2019 software tool in order to determine the optimum dimensions of the antenna and feed line for better antenna performance characteristics.

The length of the inset feeds (Wi) and length (La) of both antennas were varied to obtain better results for return loss characteristics and resonant frequency respectively. As we can notice from below figures 3,4 that as length of the inset feed changes for Antenna 1 (Figure 3.) and antenna 2 (Figure 4.) there is an impedance mismatching which results in variation in return loss characteristics and we have observed that return loss is minimum at $8.282 \mathrm{~mm}$ for Antenna 1 and $0.831 \mathrm{~mm}$ for antenna 2 from their respective edges. 


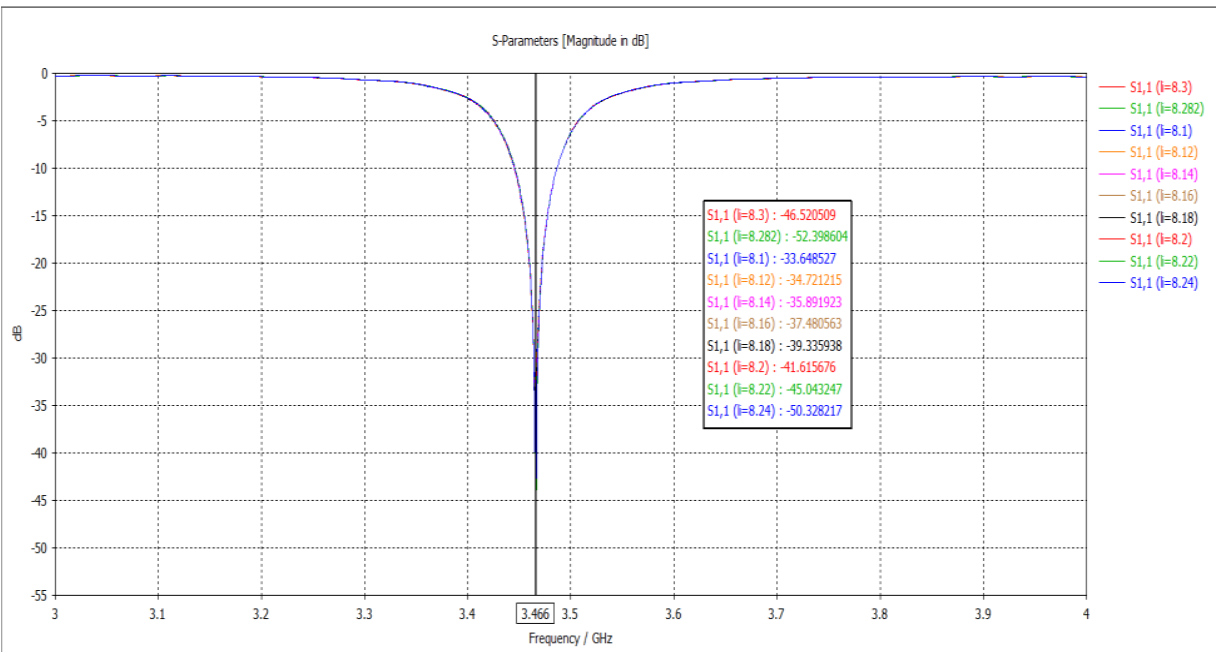

Figure 3 Effect of inset feed length variation on return loss characteristics (Antenna 1)

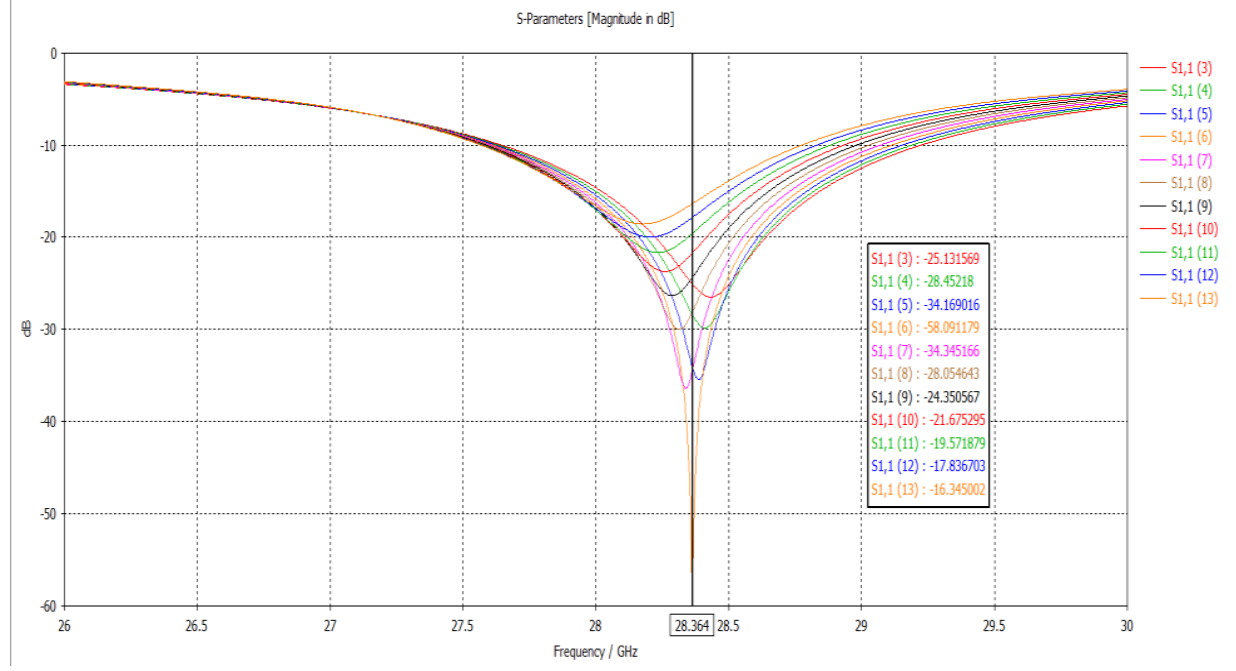

Figure 4 Effect of inset feed length variation on return loss characteristics (Antenna 2)

Similarly, the length of both the antennas was varied to return the most optimal resonant frequencies. As the length of the antennas is changed as seen for Antenna 1 in (Figure 5.) and Antenna 2 in (Figure 6.), the resonant frequency changes and we have observed that at values of $30.3 \mathrm{~mm}$ (Antenna 1) and $4.2 \mathrm{~mm}$ (Antenna 2) required resonant frequency is obtained.

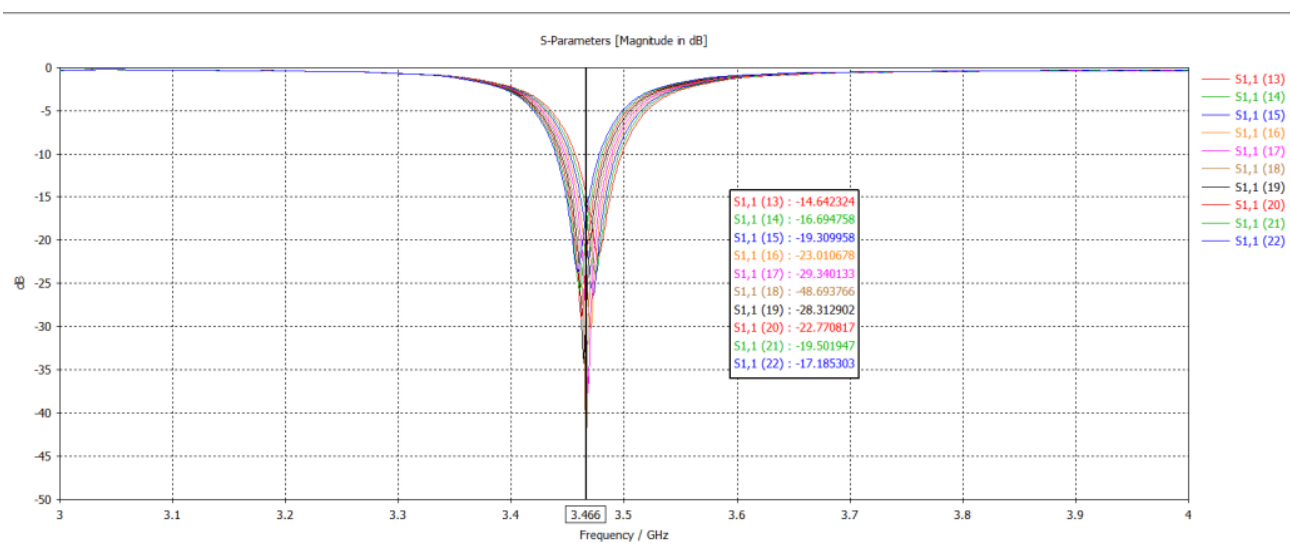

Figure 5 Effect of antenna length on resonant frequency (Antenna 1) 


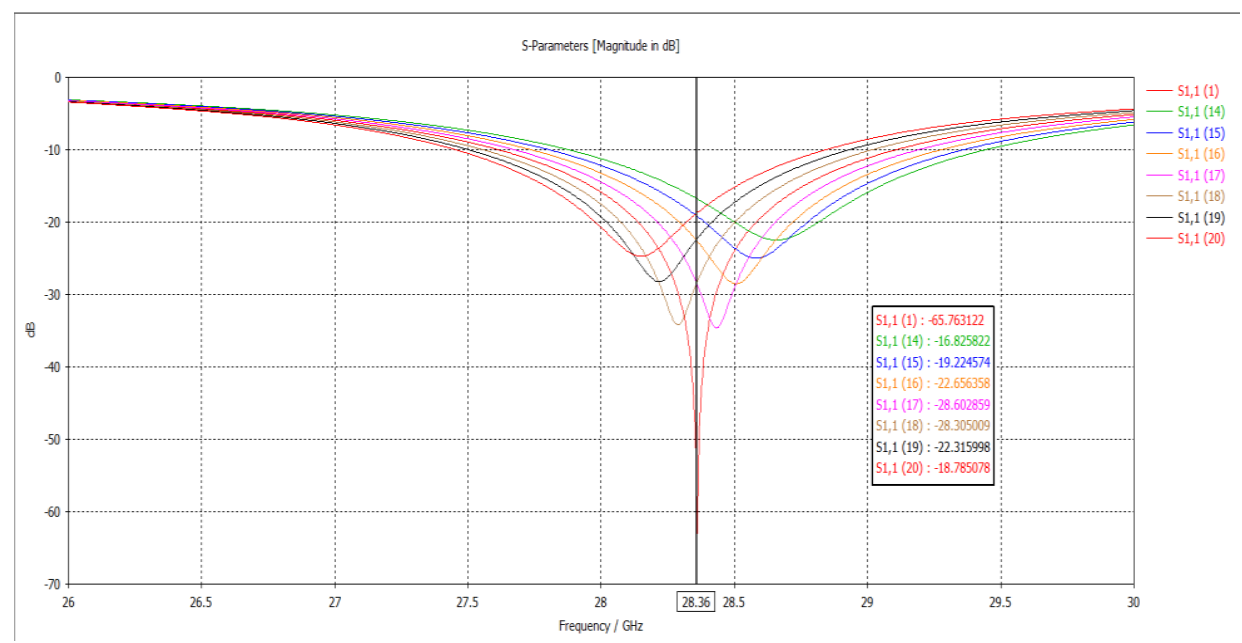

Figure 6 Effect of antenna length on resonant frequency (Antenna 2)

Optimized dimensions of the antennas are given in Table 1 and Table 2.

Table 1 Dimensions of Antenna $1(\mathrm{~mm})$

(Wg - Width of the ground plane, Lg - Length of the ground plane, Wa - Width of the antenna, La Length of the antenna, Wi - Length of the inset feed line, Li - Width of the inset feed line, Wf - Width of the transmission line, $L f$ - Length of the feed line, $H$ - Height of the substrate)

\begin{tabular}{|c|c|c|c|c|c|c|c|c|}
\hline $\mathrm{Wg}$ & $\mathrm{Lg}$ & $\mathrm{Wa}$ & $\mathrm{La}$ & $\mathrm{Wi}$ & $\mathrm{Li}$ & $\mathrm{Wf}$ & $\mathrm{Lf}$ & $\mathrm{H}$ \\
\hline 80 & 80 & 26.55 & 30.3 & 8.282 & 0.5 & 1.144 & 35.007 & 0.5 \\
\hline
\end{tabular}

Table 2 Dimensions of Antenna $2(\mathrm{~mm})$

\begin{tabular}{|c|c|c|c|c|c|c|c|c|}
\hline $\mathrm{Wg}$ & $\mathrm{Lg}$ & $\mathrm{Wa}$ & $\mathrm{La}$ & $\mathrm{Wi}$ & $\mathrm{Li}$ & $\mathrm{Wf}$ & $\mathrm{Lf}$ & $\mathrm{H}$ \\
\hline 14.96 & 17.45 & 3.05 & 4.2 & 0.831 & 0.5 & 1.144 & 10 & 0.5 \\
\hline
\end{tabular}

\section{RESULTS AND DISCUSSION}

\subsection{Antenna 1}

Performance characteristics such as return loss, radiation and gain characteristics of the antenna were studied. Figure 7 depicts the return loss characteristics of square patch antenna that resonates at $3.46 \mathrm{GHz}$ with return loss of $-52.39 \mathrm{~dB}$. The $(-10 \mathrm{~dB})$ impedance bandwidth of the antenna is $41.2 \mathrm{MHz}$ ranging from 3.4458 to $3.487 \mathrm{GHz}$. Bandwidth can also be determined using VSWR characteristics (Figure 8).

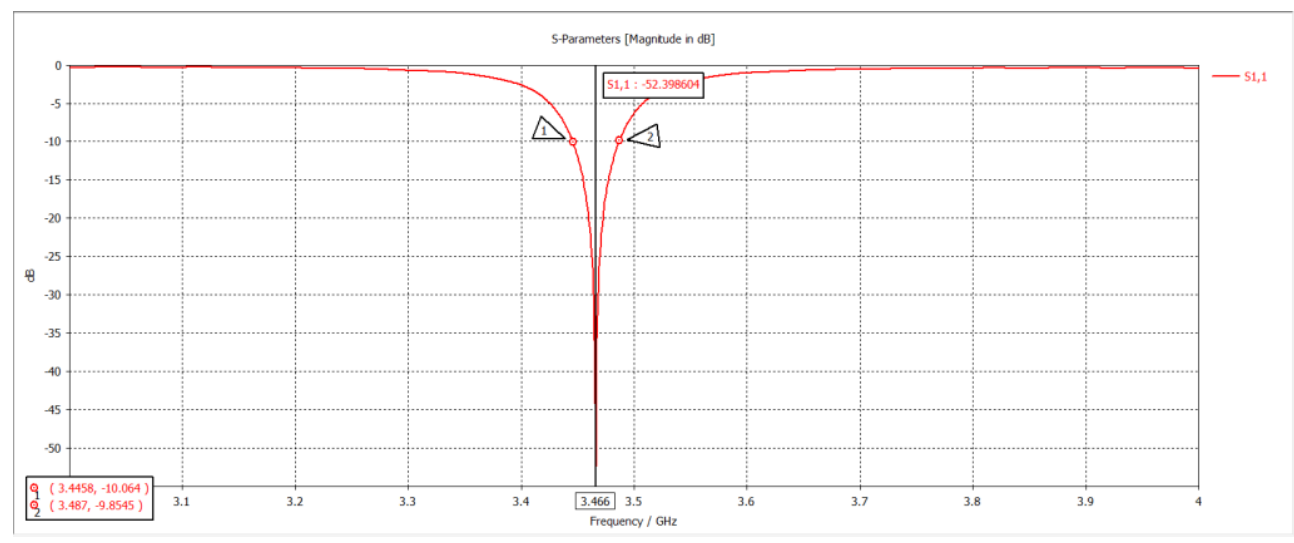

Figure 7 Return loss characteristics of Antenna 1 


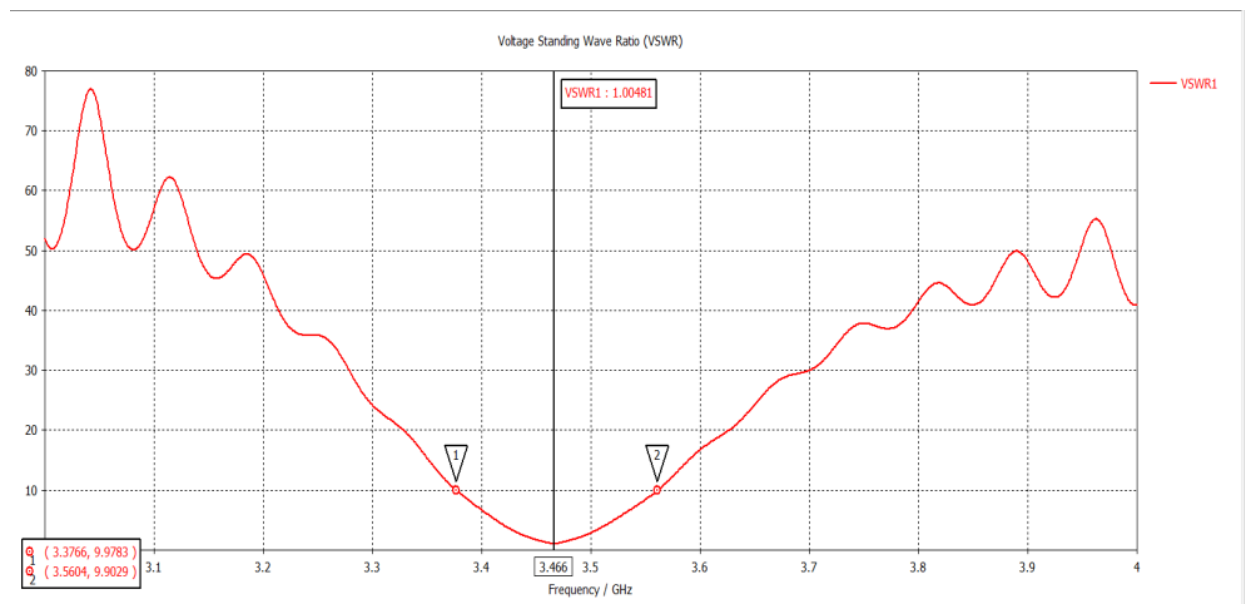

Figure 8 VSWR characteristics of Antenna 1

From Figure 9 we can notice that the radiation is in broadside direction with a gain of 8.003 $\mathrm{dBi}$ and beamwidth of $71.3^{\circ}$. Front to back ratio of the antenna is high. The gain values obtained at different frequencies within the bandwidth range of 3.4458 to $3.487 \mathrm{GHz}$ are consistent as shown in Figure 10.

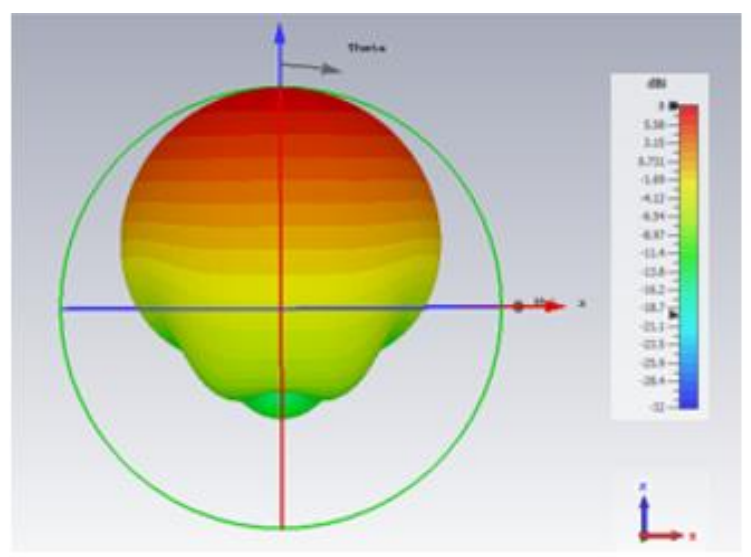

(a)

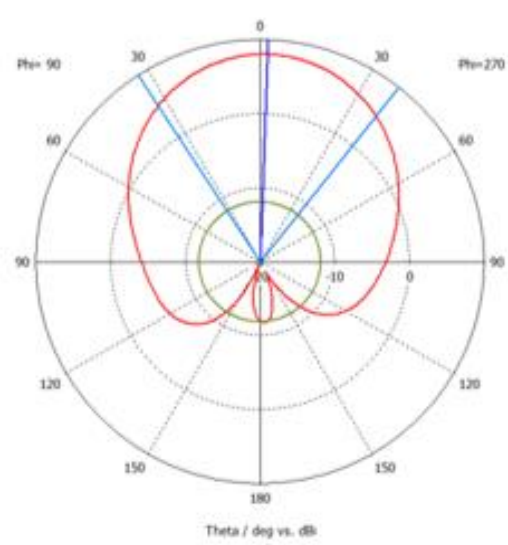

(b)

Figure 9 Radiation pattern of Antenna 1 (a) 3D radiation pattern, (b) 2D radiation pattern

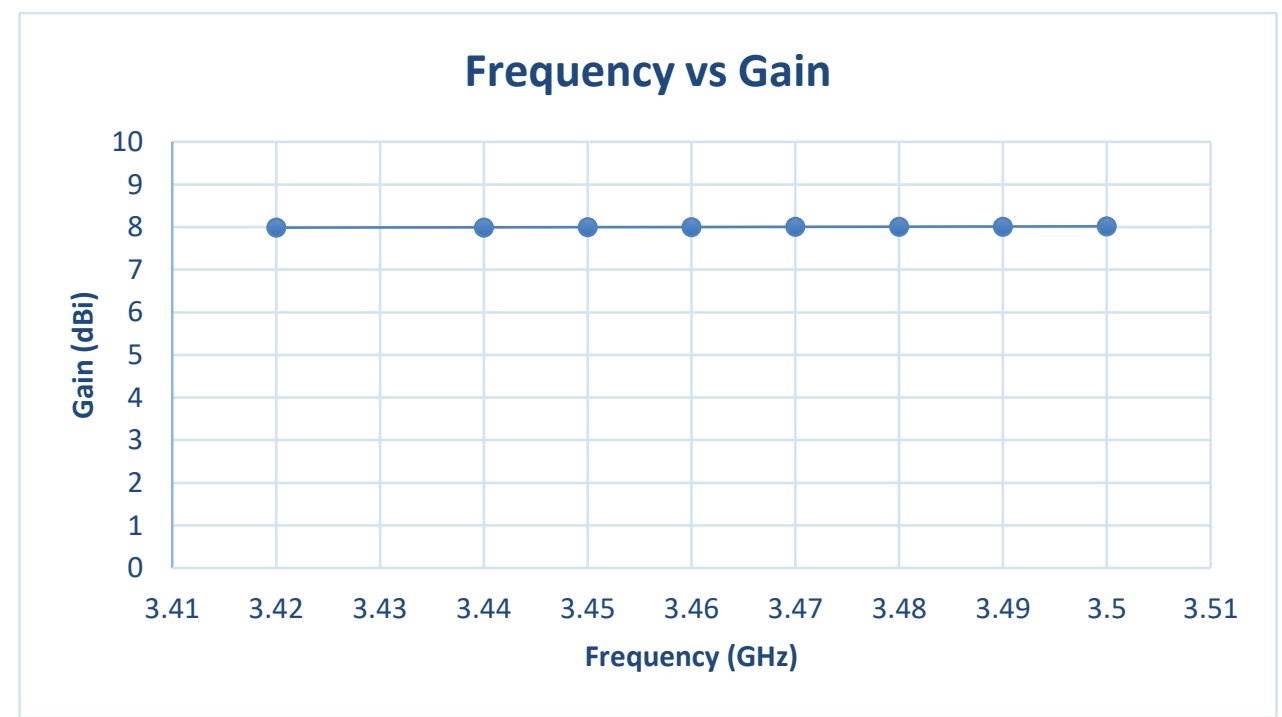

Figure 10 Gain plot at different frequencies within the bandwidth range (Antenna 1) 


\subsection{Antenna 2}

The advantage of high frequencies is that the bandwidth for communication is made broader and this means that more amount of data can be transferred at a point of time.

Figure 11 depicts the return loss characteristics of rectangular patch antenna that resonates at $28.36 \mathrm{GHz}$ with return loss of $-65.76 \mathrm{~dB}$. The $(-10 \mathrm{~dB})$ impedance bandwidth of the antenna is $1.4 \mathrm{GHz}$ ranging from 27.604 to $29.094 \mathrm{GHz}$. Bandwidth can also be determined using VSWR characteristics (Figure 12).

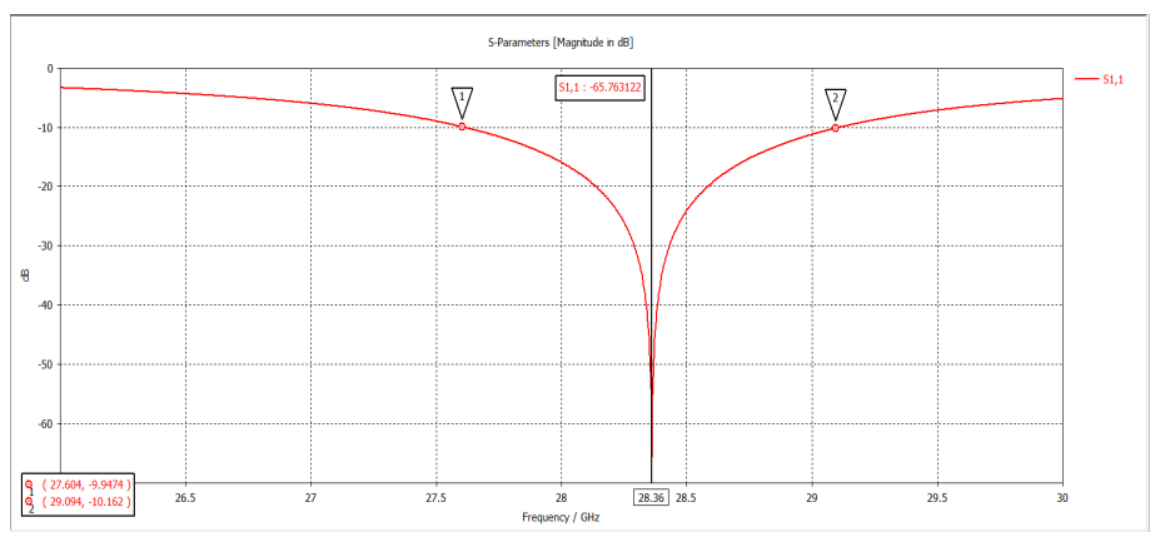

Figure 11 Return loss characteristics of Antenna 2

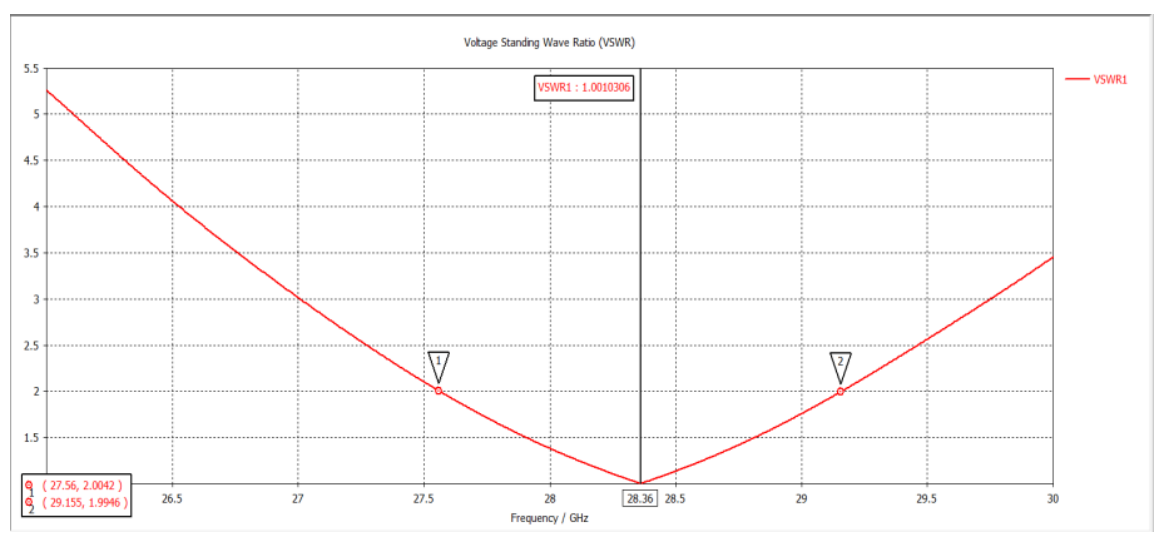

Figure 12 VSWR characteristics of Antenna 2

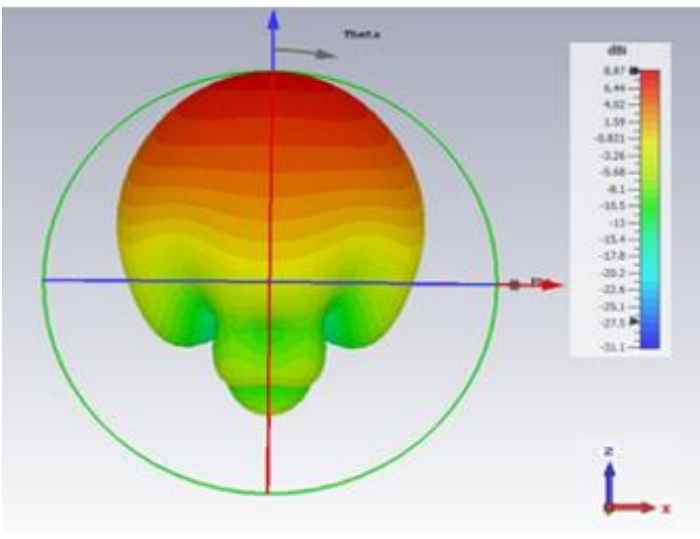

(a)

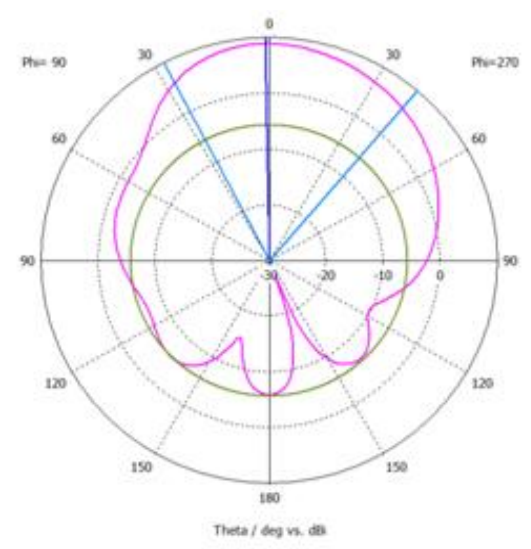

(b)

Figure 13 Radiation pattern of Antenna 2 (a) 3D radiation pattern, (b) 2D radiation pattern 
From figure 13 we can notice that the radiation is in broadside direction with a gain of 8.886 $\mathrm{dBi}$ and beamwidth of $67.8^{\circ}$. Front to back ratio of the antenna is high. The gain values obtained at different frequencies within the bandwidth range of 27.604 to $29.094 \mathrm{GHz}$ are consistent as shown in Figure 14.

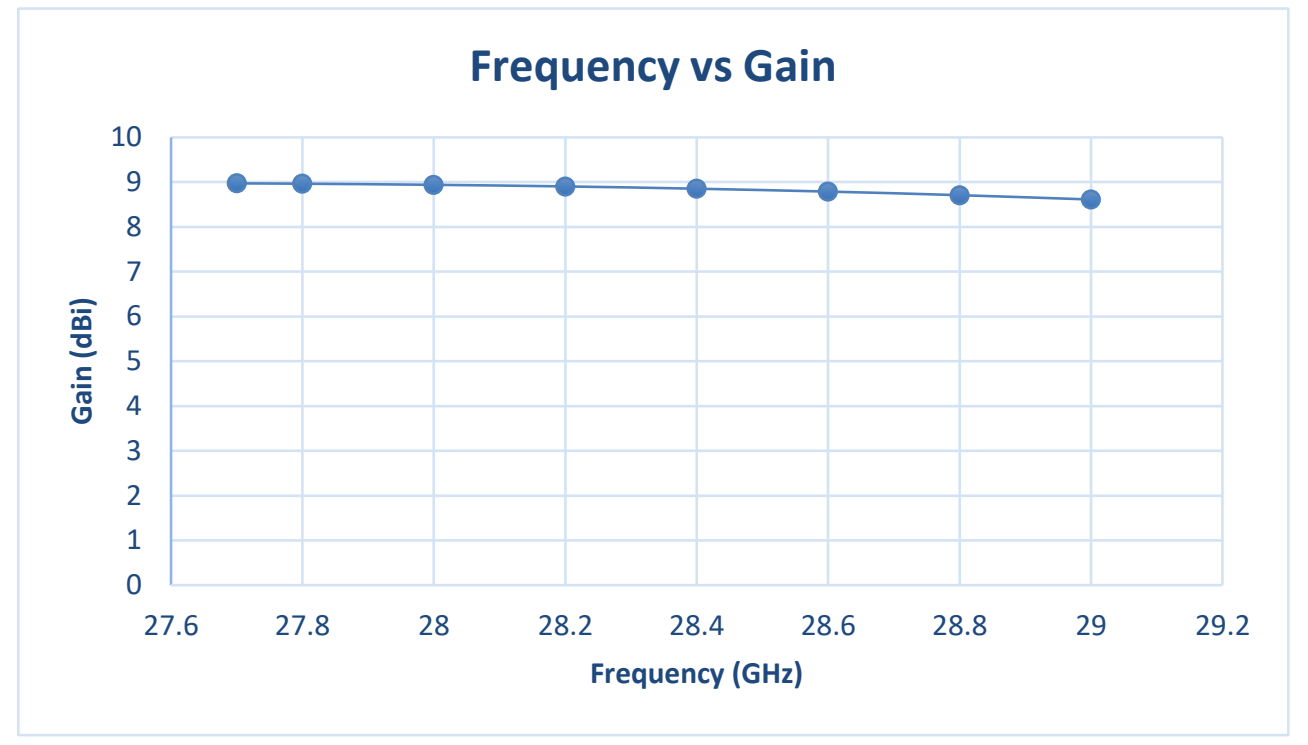

Figure 14 Gain plot at different frequencies within the bandwidth range (Antenna 2)

The proposed antenna performance was compared with other wearable antennas reported in literature (Table 3). The proposed antenna offers better gain when compared to the other ones at the $28 \mathrm{GHz}$ operating frequency.

Table 3 Comparison of wearable antennas at $28 \mathrm{GHz}$

\begin{tabular}{|c|c|c|c|l|}
\hline Reference & $\begin{array}{c}\text { Bandwidth } \\
(\mathbf{G H z})\end{array}$ & $\begin{array}{c}\text { Frequency } \\
(\mathbf{G H z})\end{array}$ & Gain (dB) & \multicolumn{1}{|c|}{ Substrate } \\
\hline$[1]$ & 2.87 & 28 & 7.5 & ABS Fingernail \\
\hline$[16]$ & 1 & 28 & 7 & PLA Medallion \\
\hline$[17]$ & 15 & 28 & 3.5 & Jeans \\
\hline$[18]$ & 2.68 & 28 & 2.1 & Rogers 5880 \\
\hline Proposed Antenna & 1.49 & 28.36 & 8.886 & Polycarbonate \\
\hline
\end{tabular}

\section{CONCLUSION}

Sub-6GHz and millimeter wave wearable antennas have been designed and proposed for $5 \mathrm{G}$ applications. The antennas operate at 3.5 and $28 \mathrm{GHz}$ with bandwidths of $41.2 \mathrm{MHz}$ (3.4458 to $3.487 \mathrm{GHz})$ and $1.49 \mathrm{GHz}(27.604$ to $29.094 \mathrm{GHz})$ respectively. Radiation pattern is unidirectional for both antennas and gain is consistent within the operating bandwidth range. Front to back ratio of the antennas is high. Because of all these inherent characteristics, the proposed antennas are well suited for IoT based solutions in 5G technology. These antennas are low profile, low cost, and easy to install and use.

\section{REFERENCES}

[1] Peter Njogu, Benito Sanz-Izquierdo, Ahmed Elibiary, Sung Yun Jun, Zhijiao Chen and David Bird, "3D Printed Fingernail Antennas for 5G Applications" in IEEE Access., vol 8, pp 228711 - 228712, Dec. 2020. 
[2] H. Rahimi, A. Zibaeenejad, and A. A. Safavi, "A novel IoT architecture based on 5G-IoT and next generation technologies," in Proc. IEEE $9^{\text {th }}$ Annu. Inf. Technol., Electron. Mobile Commun. Conf. (IEMCON), Vancouver, BC, Canada, Nov. 2018, pp. 81-88.

[3] M. Agiwal, A. Roy, and N. Saxena, "Next generation 5G wireless networks: A comprehensive survey,’' IEEE Commun. Surveys Tuts., vol. 18, no. 3, pp. 1617-1655, 3rd Quart., 2016.

[4] Insha Ishteyaq, Issmat Shah Masoodi and Khalid Muzaffar, "A compact double-band planar printed slot antenna for sub-6 GHz 5G wireless applications" in Cambridge University Press., pp. 1-2, Sep. 2020.

[5] Amruta S. Dixit and Sumit Kumar, "A Miniaturized Antipodal Vivaldi Antenna for 5G Communication Applications" in 7th International Conference on Signal Processing and Integrated Networks (SPIN)., pp. 801-802, Feb 2020.

[6] B. Sanz-Izquierdo, E. A. Parker, J. C. Batchelor, and J. Miller, "Body armour with integral high impedance surface," in Proc. 5th Eur. Conf.Antennas Propag. (EUCAP), Rome, Italy, Apr. 2011, pp. 1061-1064.

[7] A. Sabban, Novel Wearable Antennas for Communication and Medical Systems. New York, NY, USA: CRC Press, 2019.

[8] M. L. Scarpello, I. Kazani, C. Hertleer, H. Rogier, and D. V. Ginste, "'Stability and efficiency of screen-printed wearable and washable antennas,' IEEE Antennas Wireless Propag. Lett., vol. 11, pp. 838-841, 2012.

[9] A. Shafqat, F. A. Tahir, and H. M. Cheema, "A compact uniplanar tri-band antenna for wearable smart watches,', in Proc. 18th Int. Symp. Antenna Technol. Appl. Electromagn. (ANTEM), Waterloo, ON, Canada, Aug. 2018, pp. 1-3. M.

[10] B. Sanz-Izquierdo, J. A. Miller, J. C. Batchelor, and M. I. Sobhy, "Dual-band wearable metallic button antennas and transmission in body area networks," IET Microw., Antennas Propag., vol. 4, no. 2, pp. 182-190, Feb. 2010.1996.

[11] S. M. Abbas, K. P. Esselle, and Y. Ranga, "An armband-wearable printed antenna with a full ground plane for body area networks,' in Proc. IEEE Antennas Propag. Soc. Int. Symp. (APSURSI), Memphis, TN, USA, Jul. 2014, pp. 318-319.

[12] S. Hong, S. H. Kang, Y. Kim, and C. W. Jung, "Transparent and flexible antenna for wearable glasses applications,'” IEEE Trans. Antennas Propag., vol. 64, no. 7, pp. 2797-2804, Jul. 2016.

[13] I. Gani and H. Yoo, "Miniaturized scalp-implantable antenna for wireless biotelemetry," in Proc. Int. Workshop Antenna Technol. (iWAT), Seoul, South Korea, Mar. 2015, pp. 348-349.

[14] Efri Sandi, Rusmono, Aodah Diamah, and Karisma Vinda, "Ultra-wideband Microstrip Array Antenna for 5G Millimeter-wave Applications" in Journal of Communications"., vol 15, pp. 198-199, Feb 2020.

[15] W. Cheng, T. Liu, M. Hsu, Z. Tsai, and W. Sheen, " $15 \mathrm{GHz}$ propagation channel measurement at a university campus for the 5G spectrum," in Proc. IEEE Asia Pacific Microwave Conference, 2015.

[16] M. Fawaz, S. Jun, W. B. Oakey, C. Mao, A. Elibiary, B. Sanz-Izquierdo, D. Bird, and A. McClelland, "3D printed patch antenna for millimeter wave 5G wearable applications," in Proc. 12th Eur. Conf. Antennas Propagation, London, U.K., 2018, pp. 492_495. 
[17] D. Sharma, S. K. Dubey, and V. N. Ojha, "Wearable antenna for millimeter wave 5G communications," in Proc. IEEE Indian Conf. Antennas Propagation, Hyderabad, India, Dec. 2018, pp. 1_4.

[18] X. Tong, C. Liu, Y. Chen, J. Zhu, X. Yang, H. Guo, and X. Liu, “A dualmode multi-polarization millimeter wave wearable antenna for WBAN applications," in IEEE MTT-S Int. Microw. Symp. Dig., China, May 2019, pp. 1_3. 